\title{
ФАКТОРЫ УСТОЙЧИВОГО РАЗВИТИЯ В СИСТЕМЕ ФОРМИРОВАНИЯ ЗДОРОВЬЯ
}

\author{
(c) 2021 Кузнецова Алсу Мунировна \\ кандидат социологических наук, старший преподаватель кафедры управления человеческими \\ ресурсами Института управления, экономики и финансов \\ Казанский (Приволжский) федеральный университет, Казань, Россия \\ E-mail:alsu@legenda.travel
}

(c) 2021 Камашева Анастасия Васильевна

старший преподаватель кафедры управления человеческими ресурсами

Института управления, экономики и финансов

Казанский (Приволжский) федеральный университет, Казань, Россия

E-mail: as112@list.ru

\section{(c) 2021 Рыжова Ася Сергеевна}

ассистент кафедры управления человеческими ресурсами

Института управления,экономики и финансов

Казанский (Приволжский) федеральный университет, Казань, Россия

E-mail: a.s.ryzhova@yandex.ru

Исследование посвящено анализу факторов устойчивого развития системы здравоохранения и «здоровью», как структурной составляющей человеческого капитала. Автором предпринята попытка создания нового подхода к систематизации факторов, определяющих системы устойчивость здравоохранения в кризисных условиях. Актуальность исследования обусловлена возросшей степенью воздействия пандемии Ковид-19 на динамику социально-экономических процессов [9].

Объектом исследования являются факторы, определяющие устойчивость системы здравоохранения Российской Федерации. Предметом исследования выступают социально-экономические отношения, возникающие при актуализации ресурсов здоровья на различных стадиях жизненного цикла. Теоретико-методологическая и практическая значимость исследования обусловлена разработке рекомендаций по расширенному воспроизводству человеческого капитала, в частности его формирующего фактора «здоровье».

Ключевые слова: человеческий капитал, система здравоохранения, кризис системы здравоохранения, здоровье, качество жизни, устойчивое развитие, воспроизводство человеческого капитала.

Главной целью экономического роста является благосостояние хозяйствующего субъекта, что выражается в качестве и уровне жизни. Качество жизни, в отличие от категории уровня жизни, содержит в себя ряд элементов, ценность которых возрастает в момент утраты. Речь идет о ресурсе времени и здоровья. Как ни парадоксально, но эти две исследуемые категории тесно взаимосвязаны, так как являются системообразующими элементами человеческого капитала. Рассмотрим феномен упущенных возможностей в контексте капитализации базовых ресурсов человека - времени жизни и здоровья, которые могут быть капитализированы при создании благоприятных условий социально-экономической системы, наличия развивающей инфраструктуры.
В исследовании издержек упущенных возможностей анализируется необратимые процессы, которые не могут быть компенсированы в денежном эквиваленте.

Сравнительная характеристика базовых элементов человеческого капитала представлена в таблице 1.

В таблице 1 структурно представлены базовые элементы человеческого капитала и их соотношение с денежным эквивалентом, возможностью быть конвертированными в финансовый капитал. Время жизни находится в тесной корреляционной зависимости с фактором «здоровье», формирующим человеческий капитал. Однако ценность времени жизни и здоровья экстраполируется по мере нивелирования.

В связи с этим в исследовании выделяются 
Таблица 1. Базовые элементы человеческого капитала

\begin{tabular}{|l|l|l|}
\hline $\begin{array}{l}\text { Элемент, формирующий } \\
\text { человеческий капитал }\end{array}$ & $\begin{array}{l}\text { Возможность компенсации в денеж- } \\
\text { ном эквиваленте }\end{array}$ & Возможность приобретения путем покупки \\
\hline Здоровье & Косвенная & Адаптационная \\
\hline Время жизни & Отсутствует & Отсутствует \\
\hline Способности & Адаптационная & Отсутствует \\
\hline
\end{tabular}

Источник: составлено авторами по материалам исследования

этапы жизнедеятельности человека, в которых наиболее ярко проявлены фазы спада и подъема спроса и предложения на ограниченные ресурсы человеческого капитала. Проанализируем каждую из фаз формирования фактора «здоровье» подробнее. Следует уточнить, что диапазон выбран автором усредненно с учетом психофизиологических особенностей и гендерных характеристик населения Российской Федерации с учетом данных службы государственной статистики [6]. Далее приведен анализ каждого этапа развития ресурса «здоровье».

1. фаза от 0 до 7 лет - этап формирования личности (психологическое и физическое здоровье). На данной фазе жизненного цикла 100 процентов эффективность производства человеческого потенциала здоровья инвестируется и формируется родителями, близким окружением, развивающей средой. Это период дошкольного обучения. Инвестированные ресурсы в этот период подлежат 100 процентной капитализации. Рекомендуется обращать особое внимание именно дошкольному образованию, формированию стратегий по устойчивому здравоохранению, поскольку повлиять на этот процесс на последующих этапах можно будет лишь косвенно.

2. фаза от 7 до 14 лет - этап активного развития интеллектуальных способностей, активность физическая и интеллектуальная. На данном этапе рекомендуется сбалансированность интеллектуальной и физической нагрузки, инвестиции в акселератор гармоничного развития: физического, эмоционального, умственного.

3. фаза от 14 до 25 лет формирует человеческий капитал в его комплексной адаптации в социально-экономическую систему. Это период, когда накопленный либо имеющийся ресурс «здоровье» расходуется максимально активно без реверсного восстановления. Время возможности капитализации человеческих ресурсов [1].

4. фаза от 25 до 45 лет - относительно длительная фаза, характеризуется сменой пара- дигм ценностей наличия свободного времени и финансовых ресурсов. Это период активизации профессиональной самореализации, самоутверждения и возможности восприятия всего жизненного цикла целиком. Продолжительность жизни в России составляет по данным 2021 года 71,5 лет, следовательно, к 45 годам проживается 50 процентов жизненного пути при позитивном жизненном сценарии [7].

5. фаза от 45 до 60 период «урожая» и реверс на восстановление «упущенных возможностей» ресурса здоровья. Ценность времени жизни в финальной стадии 5 фазы существенно превышает 3 и 4 фазы, что также подтверждается научными исследованиями в области восприятия времени в течении жизненного цикла человека.

6. фаза от 60 до 70 лет характеризуется временем первой мудрости. Принятие необратимости упущенных возможностей и адаптационное восстановление здоровья. 6 фаза - это также фаза значительного числа психофизиологических кризисов, которые требует ресурс «здоровье». Время капитализации сменяется на период сохранения и стратегии дожития. Коэффициент дожития в России, по мнению автора исследования, требует существенной доработки и дополнительных рекомендаций, не связанных с пенсионным возрастом.

7. фаза от 70 и без временного ограничения. По мнению профессора Мясникова человек, доживший до семидесятилетнего возраста в минимальной степени обусловлен в длительности жизни наличием негативных факторов, разрушающих здоровье, таких как употребление алкоголя или курение. Данный этап характеризуется генетической расположенностью к длительности жизни.

По мнению авторов исследования, устойчивость системы здравоохранения, направленная на укрепление человеческого капитала, формируемого фактором «здоровье» следует быть 
интегрированной как целое, с учетом одномоментно всех 7 фаз жизненного цикла человека. Другими словами, применение целостного изучения жизненного цикла, а не последовательного [2]. Продолжительность жизни, как бы ни печально было это заключить, увеличивается слишком медленно, чтобы позволить рассмотреть хотя-бы 7 фаз в контексте целостной системы. Возможно, что человечество находится на той стадии развития, когда еще очень мало известно о ресурсах человека, о человеческих возможностях в области управления продолжительностью жизни и капиталом «здоровье» [3]. Проблема также заключается в том, что после определенного возраста отсутствуют готовые смыслы жизнедеятельности для людей почтенного возраста, отсутствует досуг, инфраструктура и мода на старость.

Особенно эта проблема актуальна в развивающихся странах, экстраполированная низкими пенсионными отчислениями и сложностью сохранить ресурс «здоровье» при тяжелом труде и слаборазвитом здравоохранении.

В контексте проведенного исследования авторами предлагается трактовать коэффициент дожития, как переменную от совокупного человеческого капитала или положительную ренту от фактора «здоровье».

В качестве примера приведем альтернативный сценарий исчерпывания эксплуатации фактора «здоровье» с учетом коэффициента дожития [8]. Устойчивой можно считать такую систему здравоохранения, в которой сбалансировано управление всеми фазами жизненного цикла человека от первой до седьмой в соответствии с классификацией автора исследования. Предлагается расчёт коэффициента устойчивого развития фактора «здоровья» на основе достигнутого качества жизни и базовых ресурсов здравоохранения. Разработанная авторами исследования формула расчета коэффициента устойчивого развития фактора «здоровья» выглядит следующим образом: (формула1).

$$
\text { Кзд. = Кс. э./Бч. к. }
$$

где:

Кз. д. - коэффициент устойчивости здоровья, обусловленный продолжительностью жизни и ресурсами человека; К с. э. - достигнутый потенциал системы здравоохранения в регионе; Б ч. к. - базовый человеческий капитал [5].

Формула 1 позволяет эффективно использовать материальные и нематериальные ресурсы региона, что особенно актуально в условиях нестабильности, кризиса социально-экономической системы. Недостатком разработанной методики управления ресурсом «здоровье» в социально-экономической системе является отсутствие учета фактора доверия к системе здравоохранения, что обусловлено также перегрузкой информационной среды относительно современных способов поддержания здоровья в условиях пандемии Ковид-19 [4]. Дискуссионность и глубина проблематики исследования воспроизводства фактора «здоровья» как основополагающей части человеческого капитала оставляет пространство для дальнейших научных исследований.

Таким образом, в настоящем исследовании авторами были проанализированы факторы устойчивого развития в системе формирования здоровья. Выделены основные фазы жизненного цикла, управляющее воздействие на которые позволяет эффективно и целостно управлять развитием современной системой здравоохранения, испытывающей сверхнагрузки от пандемии Ковид-19, избытка агрессивности факторов внешней среды.

\section{Библиографический список}

1. олесникова Ю.С., Фахрутдинова Е.В., Юрков Д.В. Привлечение и удержание высококвалифицированных специалистов в Республику Татарстан//Экономические науки, 2020, №12 (193), с. 246-250.

2. Сафиуллин М.Р., Ельшин Л.А., Фахрутдинова Е.В/Эффективность развития региональной высшей школы: качественно-количественный анализ (на примере Приволжского федерального округа)/Вестник высшей школы. - 2019. -№ 12. -с. 55-61.

3. Фахрутдинова Е.В., Камашева А.В., Валеев Э.Р. Статистический анализ дифференциации субъектов Российской Федерации по качеству жизни населения// Экономические науки. - 2019. -№ 12. - С. 356-362

4. Фахрутдинова Е.В., Грудина С.И. Индекс доверия как фактор устойчивости воспроизводства нематериального капитала региона/Е.В. Фахрутдинова, С.И. Грудина// Казанский экономический вестник. - 2021. № $5 .-$ C. $35-40$. 
5. Регионы России. (2020) Социально-экономические показатели. 2020: Р32 Стат. сб./Росстат. М., 2020. 1242 с.

6. Федеральная служба государственной статистики http://gks.ru/bgd/regl/b20_14p/Main. htm

7. Global Intangible Finance Tracker $\left(\mathrm{GIFT}^{\mathrm{TM}}\right) /$ an annual review of the world»s intangible value/November 2019/[Электронный ресурс https://brandfinance.com/wp-content/uploads/1/gift_2. pdf

8. Information on socio-economic indicators in Russia for the first half of 2021-Moscow: FSGS (Rosstat)/[Electronic resource]. Access mode: https://rosstat.gov.ru/storage/mediabank/centr2k-21. pdf

9. World Happiness, Trust and Deaths under COVID-19/John F. Helliwell Vancouver School of Economics, University of British Columbia Haifang Huang Associate Professor, Department of Economics, University of Alberta Shun Wang Professor, KDI School of Public Policy and Management Max Norton Vancouver School of Economics, University of British Columbia/[Electronic resource]. Access mode: https://happiness-report. s3.amazonaws. com/2021/WHR+21_Ch2. pdf 